\title{
A TRADUÇÃO DE EXPRESSÕES IDIOMÁTICAS PRESENTES NA DUBLAGEM DO SERIADO “EL CHAVO DEL 8" PARA O ENSINO DE ESPANHOL COMO LÍNGUA ESTRANGEIRA
}

\author{
LA TRADUCCIÓN DE EXPRESIONES IDIOMÁTICAS PRESENTES EN EL \\ DOBLAJE DE LA SERIE “EL CHAVO DEL 8” PARA LA ENSEÑANZA DE \\ ESPAÑOL COMO LENGUA EXTRANJERA
}

THE TRANSLATION OF IDIOMS FROM DUBBING OF THE SERIES "EL CHAVO DEL 8" FOR TEACHING SPANISH AS A FOREIGN LANGUAGE

\author{
Ariel Marcelo FERNÁNDEZ QUIROZ ${ }^{1}$ \\ Paula Tavares PINTO ${ }^{2}$
}

RESUMO: As expressões idiomáticas são construções fixas próprias de cada língua e cultura e seu ensino em língua estrangeira merece especial atenção. A tradução inconsciente dos alunos na sala de aula entra em conflito no momento de traduzir literalmente tais expressões, tendo em vista que nem todas elas possuem um equivalente gramatical e sintaticamente semelhante na língua meta. Neste artigo, esperamos oferecer uma base teórica que ajudará os docentes a entender como se posicionar perante os alunos no momento de ensinar expressões idiomáticas em espanhol e como abordar o conteúdo. Para tal, baseamo-nos na definição de expressão idiomática do Dicionário Priberam da Língua Portuguesa, nos fundamentos teóricos de expressão idiomática (XATARA, 1998), equivalência (HURTADO ALBIR, 2001), os níveis de aprendizagem de expressões idiomáticas (RIOS, 2010) e a tradução na aquisição de línguas estrangeiras (HARBORD, 1992). Para ajudar nesse processo, apresentamos quinze exemplos de expressões idiomáticas em espanhol extraídos de nove episódios do seriado mexicano "El Chavo del 8", com seus respectivos significados e equivalências em português.

PALAVRAS-CHAVE: Expressão idiomática. Equivalência. Tradução. Ensino de espanhol como língua estrangeira.

RESUMEN: Las expresiones idiomáticas son construcciones fijas de cada idioma y cultura y su enseñanza en la clase de lengua extranjera merece especial atención. La traducción inconsciente de los alumnos en la sala de clases entra en conflicto cuando se traduce literalmente tales expresiones, tomando en consideración que no todas cuentan con un equivalente gramatical y sintácticamente semejante al de la lengua

\footnotetext{
${ }^{1}$ Universidade Estadual Paulista (UNESP), São José do Rio Preto - SP - Brasil. Mestrando no Programa de Pós-graduação em Estudos Linguístico. ORCID: <http://orcid.org/0000-0001-6523-2476>. E-mail: rel.fernandezq@gmail.com

${ }^{2}$ Universidade Estadual Paulista (UNESP), São José do Rio Preto - SP - Brasil. Professora Doutora no Programa de Pós-graduação em Estudos Linguísticos, nas linhas de Estudos da Tradução e Pedagogia do Léxico e da Tradução baseada em Corpora. ORCID: 〈https://orcid.org/0000-0001-9783-2724>. E-mail: paula@ibilce.unesp.br
} 
meta. En este artículo esperamos ofrecer una base teórica que ayudará a los docentes a entender cómo posicionarse frente a los alumnos al momento de enseñar expresiones idiomáticas en español y cómo abordar el contenido, y para ello nos basamos en la definición de expresión idiomática del Dicionário Priberam da Língua Portuguesa, en los fundamentos teóricos de expresión idiomática (XATARA, 1998), de equivalencia (HURTADO ALBIR, 2001), los niveles de aprendizaje de expresiones idiomáticas (RIOS, 2001) y de traducción en la adquisición de lenguas extranjeras (HARBORD 1992) Para ayudar en ese proceso, presentamos quince ejemplos de expresiones idiomáticas en español extraídos de nueve capítulos de la serie mexicana "El Chavo del 8 ", con sus respectivos significados y equivalencias en portugués.

PALABRAS CLAVE: Expresión idiomática. Equivalencia. Traducción. Enseñanza de español como lengua extranjera.

ABSTRACT: Idioms are formulaic constructions specific to each language and culture that, in the field of teaching a foreign language, deserve special attention. The unconscious translation process performed by students in the classroom should conflict when literally translating such expressions, because not all of them have a grammatically and syntactically similar equivalent in the target language. In this article, we try to offer a theoretical basis that will help teachers understand how to position themselves in front of students when teaching idioms in Spanish and how to approach this content. To achieve this, we are based on the definition of idioms given by Dicionário Priberam da Língua Portuguesa, on the theoretical basis of idiomatic expression (XATARA, 1998), equivalence (HURTADO ALBIR, 2001), levels of learning of idiomatic expressions (RIOS, 2010), and translation in the acquisition of foreign languages (HARBORD, 1992). To help with this process, we present fifteen examples of Spanish idioms extracted from nine episodes of the Mexican series "El Chavo del 8", with their respective meanings and equivalences in Portuguese.

KEYWORDS: Idiom. Equivalence. Translation. Teaching spanish as a foreign language.

\section{Introdução}

O espanhol é conhecido por ser uma das línguas românicas mais parecidas com o português. Ao se falar entre si, e não havendo estudado a língua ou havendo aprendido o básico, falantes de espanhol e de português tentam se comunicar traduzindo literalmente as frases que querem expressar ou utilizando palavras e expressões que escutaram na televisão, leram na internet ou fazendo uso das dicas que receberam de um amigo antes de viajar para um país estrangeiro ou ainda que aprenderam por simples curiosidade. Contudo, existem expressões que, se forem traduzidas literalmente, provavelmente não serão entendidas pelo interlocutor. Esse é o caso de grande parte das expressões idiomáticas. 
Em primeiro lugar, apresentaremos o conceito de expressão idiomática segundo o Dicionário Priberam da Língua Portuguesa, que define a expressão idiomática como:

Locução ou frase cuja estrutura se fixou na língua e cujo significado não corresponde à soma dos significados isolados das palavras que a compõem, motivo pelo qual não é interpretada à letra (ex.: a expressão idiomática estar na mó de cima significa atravessar uma fase de prosperidade). (DICIONÁRIO PRIBERAM DA LÍNGUA PORTUGUESA, 2018, s/p)

Um exemplo de expressão idiomática da língua portuguesa é “abotoar o paletó”. Se analisarmos os constituintes da expressão separadamente, não nos levará ao seu significado original no português, que corresponde a morrer. A ideia dessa expressão, da mesma forma que a maioria das expressões idiomáticas, está relacionada com o seu sentido literal. A expressão "abotoar o paletó" é utilizada para dizer que alguém morreu, já que quando a pessoa morre, veste um terno (essa expressão é usada indistintamente para homens e mulheres). Em espanhol, uma expressão idiomática equivalente a "abotoar o paletó" é "estirar la pata", que faz referência à forma como morrem os pássaros. Se os falantes, tanto de português quanto de espanhol, traduzirem ambas as expressões literalmente, "abrocharse el terno" e "esticar a perna", provavelmente o interlocutor terá dificuldade em entender seu conteúdo semântico dentro de um contexto de conversação.

Ao analisarmos estudos que trabalham com o conceito e definição da expressão idiomática, destacamos o trabalho de Xatara (1998), para quem a expressão idiomática:

[...] é uma lexia complexa indecomponível, conotativa e cristalizada em um idioma pela tradição cultural. E explicamo-nos sumariamente: lexia complexa porque tem o formato de uma unidade locucional ou frasal; indecomponível porque constitui uma combinatória fechada, de distribuição única ou distribuição bastante restrita; conotativa porque sua interpretação semântica corresponde a pelo menos um primeiro nível de abstração calculada a partir da soma de seus elementos sem considerar os significados individuais destes; cristalizada porque sua significação é estável, em razão da freqüência de emprego, o que a consagra. (XATARA, 1998, p. 170)

De acordo com as definições do dicionário e da autora, podemos afirmar que uma tradução literal das expressões idiomáticas nem sempre será possível. Como as expressões idiomáticas, segundo a autora, são expressões consagradas de cada país ou cultura, no momento de traduzi-las, é necessário empregar uma das questões mais discutidas em Estudos da Tradução: a equivalência. 


\section{$O$ conceito de equivalência na tradução}

Vários autores têm definido, nas últimas décadas, o conceito de técnica de tradução e enumerado diversos tipos. Neste artigo, abordaremos apenas a definição de técnica de tradução de Hurtado Albir (2001) e apenas uma delas: a equivalência.

Uma técnica de tradução é um "procedimento, visível no resultado da tradução, que é utilizado para conseguir a equivalência tradutora de microunidades textuais ${ }^{3}$ " (HURTADO ALBIR, 2001, p. 642). No caso da equivalência, "é utilizado um termo ou expressão reconhecido (pelo dicionário ou pelo seu uso linguístico) como equivalente na língua meta, por exemplo, ao traduzir a expressão inglesa They are as like two peas para Se parecen como dos gotas de agua"' (HURTADO ALBIR, 2001, p. 270).

No exemplo da autora citado acima, podemos observar uma equivalência entre o par linguístico inglês-português, mas também podemos colocar mais uma equivalência: em português, "cara de um focinho de outro". Existem algumas expressões em inglês que, apesar de o sentido não ser literal, são bem parecidas com algumas em português e espanhol, o que também acontece nos pares linguísticos inglês-espanhol e portuguêsespanhol.

\section{O uso da tradução no ensino de línguas estrangeiras}

Conforme discutido anteriormente, um processo praticamente inconsciente que os aprendizes de línguas estrangeiras efetuam no momento de falar ou escrever é traduzir o que têm vontade de expressar. Geralmente, os professores pedem para os alunos pensarem diretamente na língua meta, para evitarem pensar na língua materna e traduzirem mentalmente o que querem expressar para posteriormente dizê-lo. Apesar de ser um processo mais complexo que requer um desenvolvimento maior da língua meta, existem autores que defendem essa estratégia por ela ser natural e inconsciente. Harbord (1992), por exemplo, explica que:

[...] a tradução/transferência é um fenômeno natural e uma parte inevitável da aquisição de uma segunda língua mesmo quando não ocorre aprendizagem formal na sala de aula. Os alunos, inevitavelmente (e mesmo inconscientemente), tentarão igualar a

${ }^{3}$ Texto Original: Procedimiento, visible en el resultado de la traducción, que se utiliza para conseguir la equivalencia traductora a microunidades textuales.

${ }^{4}$ Texto original: Se utiliza un término o expresión reconocido (por el diccionario, por el uso lingüístico) como equivalente en la lengua meta. Ej.: traducir la expresión inglesa They are as like as two peas y Se parecen como dos gotas de agua. 
estrutura da língua meta ou um item lexical com seu correlato mais próximo ou o mais comum na língua materna, independentemente de haver ou não a oferta ou a "permissão" do professor para traduzir". (HARBORD, 1992, p. 351)

Havendo estudado os conceitos de expressão idiomática e de equivalência, podemos afirmar que esse processo mental inconsciente utilizado na sala de aula não será possível (na maioria dos casos) com as expressões idiomáticas. Ao percebermos a possibilidade da tradução de expressões idiomáticas mais próximas ou distantes, destacamos o trabalho de Rios (2001), que acredita ser "possível, necessário e profícuo iniciar a inclusão sistemática das EIs [expressões idiomáticas] desde os níveis básicos de ensino/aprendizagem de LEs [línguas estrangeiras]" (RIOS, 2010, p. 46). A pesquisadora propõe a separação das EIs em níveis de aprendizagem. Desse modo, o aluno aprenderia a expressão de acordo com o nível de aprendizado em que se encontra. O nível 1 abrangeria aquelas expressões que possuem as mesmas características sintáticas, semânticas, pragmáticas e funcionais de sua língua materna, já que seriam de mais fácil memorização, pois são equivalentes nas duas línguas. A pesquisadora exemplifica a expressão em português "ter cara de", que seria "tener cara de" em espanhol. No nível 2, as expressões coincidem apenas parcialmente (intermediário). No nível 3 (avançado), as expressões apresentam equivalentes idiomáticos na LE, mas a estrutura sintática é bem diferente. Por fim, no nível 4 (superior), os idiomatismos não possuem nenhuma equivalência com a língua materna, incluindo nele os falsos cognatos.

Com a finalidade de ilustrarmos melhor a questão da tradução no ensino e aprendizagem do espanhol, apresentaremos algumas expressões idiomáticas e suas respectivas traduções presentes no seriado "Chaves", o que nos ajudará a entender o seu funcionamento.

\section{El Chavo del 8}

El Chavo del 8 (Chaves no Brasil) é uma sitcom (comédia de situação) mexicana criada por Roberto Gómez Bolaños, mais conhecido como "Chespirito”, exibida pela

\footnotetext{
5 Texto original: [...] translation/transfer is a natural phenomenon and an inevitable part of second language acquisition even where no formal classroom learning occurs. Learners will inevitably (and even unconsciously) attempt to equate a target language structure or lexical item with its closest or most common correlate in the mother tongue, regardless of whether or not the teacher offers or 'permits' translation.
} 
primeira vez em 20 de junho de 1971 pelo canal 8 e produzida pela Televisión Independiente de México, posteriormente, Televisa. A intenção desta e outras comédias de situação é fazer piadas de lugares comuns e levantar uma crítica desnaturalizando problemáticas sociais como a pobreza, a orfandade e o maltrato infantil.

O seriado mostra a vida dos moradores de uma vila mexicana, cujo protagonista é "El Chavo del 8" (“O menino do 8", devido ao programa ser transmitido pelo canal 8), um órfão de oito anos de idade que, junto com seus amigos Chiquinha e Quico, são o foco de discussões e maus entendidos com o resto da vizinhança: Seu Madruga (pai da Chiquinha), Dona Florinda (mãe do Quico), Professor Girafales (professor das crianças), Dona Clotilde (“A bruxa do 71”), o Senhor Barriga (dono da vila), entre outros. Apesar de alguns episódios terem lugar em outros locais (escola, parque, rua) a grande maioria ocorre no pátio da vila e nas casas dos moradores.

No Brasil, a dublagem do "Chaves" aconteceu nos estúdios TVS, entre 1984 e 1986 e Marshmallow (estúdios brasileiros de dublagem), de 1988 a 1992. A tradução foi feita por Potiguara Lopez, que também foi diretor de dublagem dos primeiros episódios das séries "Chaves" e "Chapolin" na Maga (outro estúdio brasileiro de dublagem).

\section{Exemplos de expressões idiomáticas}

Para exemplificarmos os níveis de aprendizagem propostos por Rios (2010), escolhemos quinze expressões idiomáticas presentes em nove episódios do seriado " $E l$ Chavo del 8". Apresentamos um quadro para cada expressão idiomática, em contexto, na versão original (espanhol) e dublada (português), seguido por uma breve análise com o significado e o equivalente em português. Dado que o nosso objetivo principal é oferecer exemplos de expressões idiomáticas e seus equivalentes em português, não abordaremos o nível 4 (as que não possuem nenhuma equivalência com a língua materna). É importante esclarecer também que algumas traduções não correspondem a uma expressão idiomática devido às escolhas do tradutor do seriado.

Nível 1 (expressões com as mesmas características sintáticas, semânticas, pragmáticas e funcionais) 
Quadro 1: exemplo extraído do episódio "A guerra é de terra ${ }^{6 "}$

Don Ramón: no le paren hasta que dejen este patio tan limpio como un espejo.

Chilindrina: ¿sí, verdad? ¿Y por qué no nos ayuda el señor Barriga? Él fue el que más ensució.

Don Ramón: ¿pero quién empezó primero? Además, abusan tanto del señor Barriga que algún día tenía que perder los estribos.

Chilindrina: ni que fuera caballo. Português

Seu Madruga: e vocês já sabem, não parem até que esse pátio esteja limpo como um espelho.

Chiquinha: sim, tá bom, mas porque o senhor Pança não ajuda a gente? Afinal foi ele quem mais sujou.

Seu Madruga: Tá, mas quem foi que começou? E tem mais, abusam tanto do Barriguinha que um dia ele tinha que perder as estribeiras.

Chiquinha: nem que fosse um cavalo.

Fonte: Elaboração própria

"Perder los estribos" significa perder o controle numa situação de estresse ou perder a paciência. Em português, o tradutor optou por uma equivalência: "perder as estribeiras".

Quadro 2: exemplo extraído do episódio "O Chiclete grudou no chapéu ${ }^{7 "}$

\begin{tabular}{|l|l|}
\hline \multicolumn{1}{|c|}{ Espanhol } & \multicolumn{1}{c|}{ Português } \\
\hline $\begin{array}{l}\text { Quico: } \text { me lo compró mi mami y le costó un ojo de } \\
\text { la cara. }\end{array}$ & $\begin{array}{l}\text { Quico: ganhei da minha mamãe e custou o olho da } \\
\text { chavo: ¿se quedó tuerta? }\end{array}$ \\
$\begin{array}{ll}\text { cara. } \\
\text { Quico: que le costó mucho dinero, tonto. }\end{array}$ & $\begin{array}{l}\text { Chaves: ela ficou cega? } \\
\text { Quico: que lhe custou muito dinheiro, besta. }\end{array}$ \\
\hline
\end{tabular}

Fonte: Elaboração própria

"Costar (algo) un ojo de la cara" significa custar muito caro ou realizar uma tarefa com muito trabalho e sacrifício. Em português, o tradutor optou por uma equivalência: "custar o olho da cara".

Quadro 1: exemplo extraído do episódio "O professor apaixonado ${ }^{8 "}$

\begin{tabular}{|c|c|}
\hline & \\
\hline $\begin{array}{l}\text { Profesor Girafales: bu } \\
\text { es un hombre de muc } \\
\text { de asuntos y yo me atr } \\
\text { Don Ramón: eso sí. } \\
\text { culpa de que las mu } \\
\text { ¿no? Es cuestión d } \\
\text { atractivo masculino. } \\
\text { Pero tratándose de D } \\
\text { gusto le vov a d }\end{array}$ & $\begin{array}{l}\text { o de } \\
\text { tem } \\
\text { o? É } \\
\text { lino. } \\
\text { Dona } \\
\text { dar }\end{array}$ \\
\hline
\end{tabular}

Fonte: Elaboração própria

\footnotetext{
${ }^{6}$ Disponível em: <https://www.youtube.com/watch?v=WS7LyOfqSyk> (português);

<https://www.youtube.com/watch?v=MBs0W0B1AGI> (espanhol)

${ }^{7}$ Disponível em: <https://www.youtube.com/watch?v=QzgrP_TMamA > (português); https://www.youtube.com/watch?v=ALpT7qjBAMA (espanhol)

${ }^{8}$ Disponível em: <https://www.youtube.com/watch?v=f4fB1DK7u-o> (português);

$<$ https://www.youtube.com/watch?v=eT4b7_2shJs> (espanhol)
} 
“Caer (rendido) a los pies (de alguien)” significa fazer com que alguém não se resista ao próprio charme. Em português, o tradutor optou por uma equivalência: "cair a seus pés".

Quadro 2: exemplo extraído do episódio "Lutador de boxe"

\begin{tabular}{|l|l|}
\hline \multicolumn{1}{|c|}{ Espanhol } & \multicolumn{1}{c|}{ Português } \\
\hline Chavo: ¿todavía sigue de boxeador? & Chaves: e ainda é um lutador? \\
Don Ramón: No, Chavito, no. No, ya no, aunque & Seu Madruga: não, Chavinho, não. Não, eu não, \\
todavía estoy en forma. & mas ainda estou em forma. \\
Chavo: en forma de alambre. & Chaves: em forma de arame. \\
\hline
\end{tabular}

Fonte: Elaboração própria

"Estar en forma" significa estar em bom condicionamento físico. Em português, o tradutor optou por uma equivalência: "estar em forma".

Quadro 3: exemplo extraído do episódio "Lutador de boxe"

\begin{tabular}{|l|l|}
\hline \multicolumn{1}{|c|}{ Espanhol } & \multicolumn{1}{c|}{ Português } \\
\hline $\begin{array}{l}\text { Don Ramón: ahora vamos a ver cómo tiras un } \\
\text { golpe. }\end{array}$ & Seu Madruga: agora vamos ver como dá um soco. \\
Chavo: Sí. & Chaves: sim. \\
(El Chavo le da un golpe en la cara a Don Ramón) & Seu Madruga: mas espere até que eu te avise. \\
Don Ramón: pero espérate hasta que yo te diga. & Chaves: ora, mas não se irrite. \\
Chavo: bueno, pero no se enoje. & Seu Madruga: está bem. Vamos ver, fique em \\
Don Ramón: está bien. Vamos a ver, ponte en & guarda. \\
guardia. & Chaves: quê? \\
Chavo: ¿qué? & Seu Madruga: para que fique em guarda. \\
Don Ramón: que te pongas en guardia. & \\
\hline
\end{tabular}

Fonte: Elaboração própria

"Ponerse en guardia" significa preparar-se para lutar, especialmente falando em esportes de luta. Em português, o tradutor optou por uma equivalência: "ficar em guarda”.

Nível 2 (expressões coincidem apenas parcialmente)

Quadro 6: exemplo extraído do episódio "Refrescos numa fria"10"

\begin{tabular}{|l|l|}
\hline \multicolumn{1}{|c|}{ Espanhol } & \multicolumn{1}{c|}{ Português } \\
\hline Quico: Yo quiero de esta. & Quico: Eu quero desse aqui. \\
Chavo: No, no, de esa no... & Chaves: Não, não, desse não... \\
Quico: ¿Por qué no me vas a dar de esa? & Quico: Por que não pode me dar desse? \\
Chavo: No, esa no te la puedo ... & Chaves: Não, não, desse eu não posso... \\
Quico: Me tienes que dar de esa, ¿cómo no? & Quico: Você tem que me dar desse, como não \\
Chavo: No, de esta no te voy a dar... & posso? \\
\hline
\end{tabular}

${ }^{9}$ Disponível em: <https://www.youtube.com/watch?v=Rihiqn0qxJc> (português);

$<$ https://www.youtube.com/watch?v=lZU0HeQeTRw> (espanhol)

${ }^{10}$ Disponível em: <https://www.youtube.com/watch?v=MasiY6Awwis> (português);

$<$ https://www.youtube.com/watch?v=9QmHgSuI7gg > (espanhol). 
Quico: Yo soy el cliente.

Chavo: No...

Quico: ¡Ya cállate, cállate, cállate, que me desesperas! Como yo soy el que va a dar el peso, yo voy a tomar el agua que me dé mi regalada gana.

Fonte: Elaboração própria
Chaves: Não, esse eu não posso dar porque... Quico: Eu que escolho.

Chaves: Não...

Quico: Cale-se, cale-se, cale-se você me deixa louco! Como sou eu quem vai pagar a conta, eu vou tomar a droga do refresco que me der na telha.

"Hacer algo que se dé la regalada gana" ou "hacer lo que se dé la gana", traduzido literalmente, "fazer o que der vontade", significa fazer algo que é desejado sem se importar com a opinião dos outros. Em português, o tradutor optou por uma equivalência: "fazer o que der na telha".

Quadro 7: exemplo extraído do episódio "Refrescos numa fria"

\begin{tabular}{|c|c|}
\hline Espanhol & Português \\
\hline $\begin{array}{l}\text { Señor Barriga: Nada más quería saber si habías } \\
\text { visto tú a Don Ramón }\end{array}$ & $\begin{array}{l}\text { Senhor barriga: Nada, eu só queria saber se você } \\
\text { tinha visto o Seu Madruga. }\end{array}$ \\
\hline Quico: ¿Le viene a cobrar la renta? & Quico: Veio cobrar o aluguel? \\
\hline $\begin{array}{l}\text { Señor Barriga: Sí, y si no me paga, ¡hoy mismo lo } \\
\text { pongo de patitas en la calle! }\end{array}$ & $\begin{array}{l}\text { Senhor Barriga: Sim, e se ele não pagar, hoje } \\
\text { mesmo eu o ponho no meio da rua! }\end{array}$ \\
\hline
\end{tabular}

Fonte: Elaboração própria

"Poner (a alguien) de patitas en la calle", traduzido literalmente, "pôr alguém com os pezinhos na rua", significa expulsar alguém de algum lugar, por exemplo, de uma casa ou do trabalho. Em português, o tradutor optou por uma equivalência: "pôr alguém no meio da rua".

Quadro 8: exemplo extraído do episódio "Mais vale uma noite bem dormida que uma boa comida" ${ }^{11 "}$

\begin{tabular}{|l|l|}
\hline \multicolumn{1}{|c|}{ Espanhol } & \multicolumn{1}{|c|}{ Português } \\
\hline $\begin{array}{l}\text { Don Ramón: Ya les dije que estoy débil por el } \\
\text { insomnio. Han de saber que hasta ahorita llevo } \\
\text { siete noches en vela. }\end{array}$ & $\begin{array}{l}\text { Seu Madruga: Eu já disse que estou fraco pela } \\
\text { insônia. Imaginem só que eu já passei sete noites } \\
\text { em claro. }\end{array}$ \\
\hline Quico: ¿Le cortaron la luz? & \begin{tabular}{l} 
Quico: Esqueceu de apagar a luz? \\
\hline
\end{tabular}
\end{tabular}

Fonte: Elaboração própria

"Pasar la noche en vela", traduzido literalmente, "passar a noite em vela", significa não conseguir dormir durante a noite, por exemplo, em casos de insônia. Em português, o tradutor optou por uma equivalência: "passar a noite em claro".

${ }^{11}$ Disponível em: <https://www.youtube.com/watch?v=npUX9sEHuZc> (português); <https://www.youtube.com/watch?v=Hqa3172At40> (espanhol). 
Quadro 9: exemplo extraído do episódio "O concurso de beleza ${ }^{12 "}$

\begin{tabular}{|l|l|}
\hline \multicolumn{1}{|c|}{ Espanhol } & \multicolumn{1}{c|}{ Português } \\
\hline Doña Florinda: detesto a los hombres. & Dona Florinda: eu detesto os homens. \\
Doña Clotilde: yo no los aguanto. & Dona Clotilde: eu não os aguento. \\
Chilindrina: yo no los puedo ver ni en pintura. & Chiquinha: eu não os posso ver nem em pintura. \\
\hline
\end{tabular}

Fonte: Elaboração própria

"No poder ver a alguien ni en pintura", traduzido literalmente, "não poder ver alguém nem em pintura”, significa sentir muita aversão por alguém até o ponto de não poder vê-lo. Em português, o tradutor optou por uma tradução literal, porém, por tratarse de uma expressão idiomática do nível 2 e não do nível 1, a escolha não foi a mais adequada. Um equivalente dessa expressão é "não querer ver alguém nem pintado" ou "não querer ver alguém nem pintado de ouro".

Nível 3 (expressões que apresentam equivalentes, mas cuja estrutura sintática é diferente)

Quadro 10: exemplo extraído do episódio "Refrescos numa fria"

\begin{tabular}{|l|l|}
\hline \multicolumn{1}{|c|}{ Espanhol } & \multicolumn{1}{c|}{ Português } \\
\hline Chavo: ¿Otra? & Chaves: Outro? \\
Señor Barriga: No. & Senhor Barriga: Não. \\
Chavo: Sí, mire, le conviene, así le digo dónde está & Chaves: Sim, olha, é bom, assim eu digo onde está \\
Don Ramón... & o Seu Madruga. \\
Señor Barriga: No quiero saber nada. & Senhor Barriga: Não quero saber nada. \\
Chavo: Para que sepa usted dónde... & Chaves: Para saber onde... \\
Señor Barriga: No quiero nada. & Senhor Barriga: Não quero nada. \\
Chavo: Es que así le digo dónde... & Chaves: Então, para que o senhor saiba onde... \\
Señor Barriga: No quiero. Me has estado tomando \\
el pelo, Chavo. & Senhor Barriga: Não quero. Eu já estou com dor \\
\hline Fonte: & de barriga. \\
\hline
\end{tabular}

Fonte: Elaboração própria

"Tomarle el pelo a alguien", traduzido literalmente "puxar o cabelo de alguém", significa fazer zombaria, rir-se de alguém. Em português, por desconhecimento, má interpretação da expressão ou por algum motivo que ignoramos, o tradutor optou por uma frase diferente considerando que, nesta cena, o personagem não aparece na tela, o que lhe deu mais liberdade. Alguns equivalentes seriam "tirar um sarro de alguém" e “estar de brincadeira com alguém".

${ }^{12}$ Disponível em: <https://www.youtube.com/watch?v=G71PFpfHDc0> (português);

<https://www.youtube.com/watch?v=ZV6Ah1m_Zrw> (espanhol) 
Quadro 11: exemplo extraído do episódio "A escolinha do Professor Girafales ${ }^{13 "}$

\begin{tabular}{|c|} 
Espanhol \\
\hline Profesor Girafales: $Y$ a todos ustedes les advierto
\end{tabular} una cosa: a la escuela se viene a aprender, no a perder el tiempo jugando a los novios y a los enamorados. Eso puede estar bien para muchachos que tienen mayor edad, pero no para niños que apenas están rompiendo el cascarón.

Fonte: Elaboração própria

"Romper el cascarón” ou "salir del cascarón”, traduzido literalmente, "quebrar a casca do ovo" ou "sair da casca do ovo", significa amadurecer, afastar-se do colo da mãe. Em português, o tradutor optou por uma tradução literal, porém, por tratarse de uma expressão idiomática do nível 2 e não do nível 1, a escolha não foi a mais adequada. Um equivalente dessa expressão é "virar gente".

Quadro 12: exemplo extraído do episódio "Um banho para o Chaves ${ }^{14 "}$ Espanhol Português

Chilindrina: pero si todo iba tan bien, pero tenía Chiquinha: estava indo tudo tão bem, mas sua mãe que llegar tu madre a meter la pata.

Fonte: Elaboração própria

"Meter la pata", traduzido literalmente, "meter a pata", significa falar ou fazer algo inoportuno ou inapropriado. Em português, o tradutor optou por uma tradução literal, porém, por tratar-se de uma expressão idiomática do nível 2 e não do nível 1, a escolha não foi a mais adequada. Um equivalente dessa expressão é "dar um fora" ou "dar bola fora".

Quadro 13: exemplo extraído do episódio "Um banho para o Chaves"

\begin{tabular}{|l|l|}
\hline \multicolumn{1}{|c|}{ Espanhol } & \multicolumn{1}{c|}{ Português } \\
\hline $\begin{array}{l}\text { Chilindrina: } \text { Olvídalo, } \text { ique se me está prendiendo } \\
\text { el foco! }\end{array}$ & $\begin{array}{l}\text { Chiquinha: Esqueça, está me ocorrendo uma } \\
\text { coisa! }\end{array}$ \\
\hline Quico: ${ }_{\text {¿Es que te falta aceite? }}$ &
\end{tabular}

Fonte: Elaboração própria

"Prender(se) el foco", traduzido literalmente, "prender(-se) o foco", significa ter uma ideia no momento oportuno. Em português, provavelmente por não ter encontrado um equivalente ou por motivos que ignoramos, o tradutor optou por uma explicação da expressão. Um equivalente dessa expressão é "ter uma luz".

\footnotetext{
${ }^{13}$ Disponível em: <https://www.youtube.com/watch?v=PBW68c73wdM> (português);

$<$ https://www.youtube.com/watch?v=2-p65TosMPg> (espanhol)

${ }^{14}$ Disponível em: <https://www.youtube.com/watch?v=xxafBZQIKOY> (português);

<https://www.youtube.com/watch?v=NuHZBrU89VQ> (espanhol)
} 
Quadro 14: exemplo extraído do episódio "Um banho para o Chaves"

\begin{tabular}{|c|c|}
\hline & \\
\hline hilin & vai saber \\
\hline
\end{tabular}

Fonte: Elaboração própria

"Echar aguas", traduzido literalmente, "jogar águas", significa pedir para alguém que avise se alguém vem enquanto você faz algo indevido. Em português, o tradutor optou por uma equivalência: "dar uma olhada".

Quadro 15: exemplo extraído do episódio "O Chiclete grudou no chapéu"

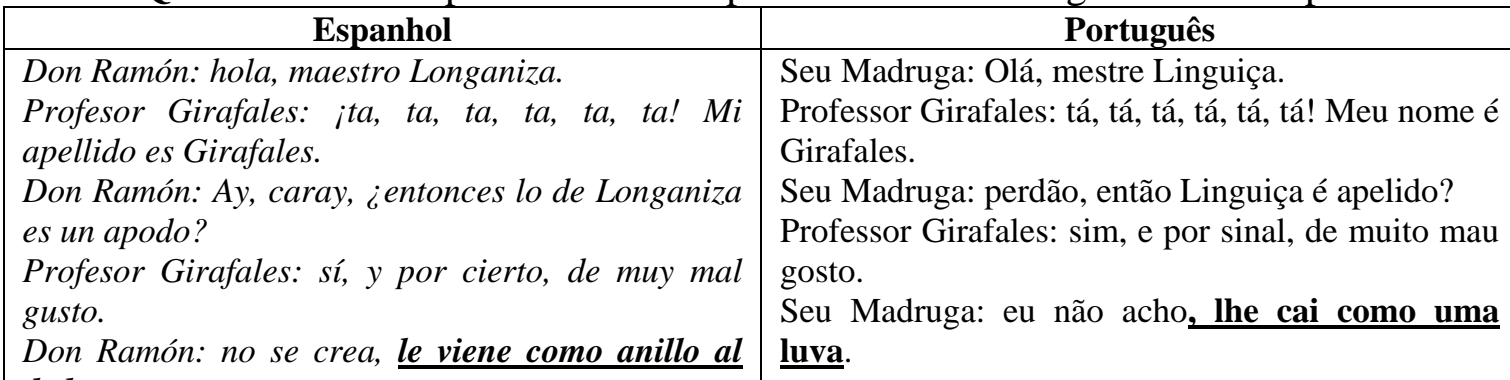

dedo.

Fonte: Elaboração própria

"Venir (algo) como anillo al dedo", traduzido literalmente, "vir (algo) como anel ao dedo", significa acontecer algo no momento preciso ou coincidir em algo com muita precisão. Em português, o tradutor optou por uma equivalência: "cair como uma luva".

\section{Considerações finais}

As expressões idiomáticas são construções próprias de cada língua/cultura que devem ser tratadas com muito cuidado na sala de aula, visto que a tradução literal das mesmas pode causar estranhamento entre os interlocutores, dependendo da sua complexidade. Entendemos que o trabalho dos tradutores do seriado "El Chavo del 8" não tenha sido fácil. As restrições próprias da tradução audiovisual, e ainda no caso da dublagem, dificultaram o trabalho. Além disso, nem sempre em todos os casos conseguiram estabelecer equivalentes precisos para cada expressão idiomática (por exemplo, a imagem tem que coincidir com o diálogo dos personagens). Considerando que nosso trabalho foi oferecer equivalentes para cada expressão idiomática, não levamos em consideração tais restrições e conseguimos levantar todos os equivalentes com sucesso. Em relação ao ensino de expressões idiomáticas na sala de aula de 
maneira didática e interessante para os alunos, a proposta de Rios (2010), aliada à escolha de expressões idiomáticas retiradas do seriado "El Chavo del 8", atenderia aos níveis de aprendizagem definidos neste artigo e poderia ser uma proposta relevante de ensino de expressões idiomáticas em espanhol.

AGRADECIMENTOS: Agradecemos mais uma vez ao Conselho Nacional de Desenvolvimento Científico e Tecnológico (CNPq) e ao Programa Convênio de Pósgraduação (PEC-PG) pela oportunidade de desenvolver pesquisas no Brasil.

\section{REFERENCIAS}

DICIONÁRIO PRIBERAM DA LÍNGUA PORTUGUESA. Priberam dicionário.

Disponível em: <https://www.priberam.pt/dlpo/>. Acesso em: 28 jan. 2018.

HARBORD, J. The use of the mother tongue in the classroom. ELT Journal, v. 46, n. 4, out., 1992.

HURTADO ALBIR, A. Traducción y traductología. 3 ed. Madrid: Cátedra, 2001. p. 648.

RIOS, T.H.C. A descrição de idiomatismos nominais: proposta fraseográfica português-espanhol. Tese (Doutorado em Estudos Linguiísticos) área de Análise Lingüística- Instituto de Biociências, Letras e Ciências Exatas da Universidade Estadual Paulista Júlio de Mesquita Filho, São José do Rio Preto, 2010.

XATARA, C. M. Tipologia das expressões idiomáticas. Alfa, São Paulo, v. 42, p. 169176, 1998.

\section{Como referenciar este artigo}

FERNÁNDEZ QUIROZ, A. M.; PINTO, P. T. A tradução de expressões idiomáticas presentes na dublagem do seriado "el chavo del 8" para o ensino de espanhol como língua estrangeira. Rev. EntreLínguas, v.4, n.1, p. 4-16, jan./jun. 2018. E-ISSN: 24473529. DOI: 10.29051/rel.v4.n1.2018.10897.

Submetido em: 20/12/2018

Revisões requeridas: $15 / 01 / 2018$

Aprovação final em: 20/02/2018 